\title{
Ultra Low Temperature Process Effects on Micro-Scale Abrasion of Tool Steel AISI D2
}

\author{
Sílvio José Gobbi ${ }^{1, *}$, Vagner João Gobbi ${ }^{1}$ and Gustavo Reinke ${ }^{1}$ \\ 1 Faculty of Technology, University of Brasília, UnB, Brasília, DF, 70910-900, Brazil; \\ vagnergobbi@yahoo.com.br (V.J.G.); gustav.reinke@gmail.com (G.R.) \\ * Correspondence: silviogobbi2@gmail.com; Tel.: +55 61 3107-1136
}

\begin{abstract}
Ultra Low Temperature Process (ULTP) involves the material cooling in temperatures close to the liquid nitrogen $\left(-196{ }^{\circ} \mathrm{C}\right)$, which is different from the cold-treatment $(\mathrm{CT})$ made in temperatures close to $-80^{\circ} \mathrm{C}$. ULTP treatments could raise the tool steel wear resistance through microstructural change that occurs on the material, enhancing, that way, the tools and dies lifetime. To investigate the impact on the wear resistance of tool steel AISI D2, micro abrasive wear tests were carried out and an analysis based on the Archard's law was considered, evaluating specimen mass loss by laser interferometry. Micro hardness tests, X-ray diffractometry, scanning and optical microscopy and quantitative evaluation of carbides with image analysis were carried out aiming to material characterization. Micro-scale abrasion tests have shown a wear coefficient $\mathrm{k}$ about 1.73E-7 e $2.61 \mathrm{E}-7 \mathrm{~mm}^{3} / \mathrm{N} . \mathrm{mm}$ to the specimens that received the ULTP phase and $3.12 \mathrm{E}-7 \mathrm{~mm} / \mathrm{N} . \mathrm{mm}$ to the conventional thermal treatment, representing a wear resistance increase of $16.3-44.5 \%$ to cryogenically treated specimens. The results demonstrated a micro hardness improvement, ranging from $0.9-4.7 \%$ for the cryogenically treated specimens, when compared to the bulk material. This effect is related, mainly, to the retained austenite transformation in martensite and to the increase in the amount of fine secondary carbides dispersed in the martensitic matrixes of cryogenically treated specimens with ULTP. The best wear resistance improvements, on micro-scale, were achieved when the ULTP step is performed immediately after tempering.
\end{abstract}

Keywords: Micro-Scale Abrasion; Ultra Low Temperature Process (ULTP); Tool Steel AISI D2;

\section{Introduction}

Tools for the metal moulding are essentials for the metallic parts manufacturing in many sectors [1]. On cutting tools, stamping and punching, the tools are exposed to high contact conditions, including high loads, high contact pressures, high contact temperatures and wear $[2,3]$. The steel used in D2 tools, with high carbon and chrome rates, have extremely high wear and abrasion resistance [4]. Although it is highly resistant to wear, it has been observed that under severe conditions there are wear failures, mainly due to the low surface hardness $[5,6]$.

Traditionally, forming tools are thermally treated under vacuum to obtain tempered martensite microstructure and uniform carbide distribution, which gives sufficient fracture toughness in the working hardness and acceptable wear resistance [2]. The use of a suitable combination of carbides in the structure of the tool material also affects the properties [7]. By optimizing the heat treatment parameters and using additional thermal and thermochemical processes, the tool steel properties and wear resistance can be improved and adjusted for a specific application [8-16]. It is reported that the deep cryogenic treatment of rapid tempered steel and tempered tools increases the hardness, reduces the consumption of tools and downtime for assembly equipment, leading to a cost reduction of about $50 \%$ [8].

The deep cryogenic treatments (DCT) or Ultra Low Temperature Process (ULTP) is a slow and controlled process in which a material is cooled to temperatures around $-196^{\circ} \mathrm{C}$ and then heated to environment temperature. It has been used, as an alternative, to improve the wear resistance (not only on the surface but also in the core) of tool steels, besides promoting better dimensional stability 
[17-23]. The better results from this kind of treatment distinguishes the ULTP from the traditional sub-zero (performed at temperatures of approximately -50 to $-80^{\circ} \mathrm{C}$, achieved mainly with dry ice as a cooling agent and being popularly called cold treatment (CT) [13, 24, 25]. The sub-zero treatments achieved industrial acceptance and has been an important part of the tool steel commercial cycle treatment over the last decades [13, 21, 24, 26]. Nowadays, it is accepted that the improvement in wear resistance by deep cryogenic treatment is considerably higher than that achieved by the sub-zero treatment $[13,18,21,26]$. The main mechanisms of deep cryogenic treatment with the use of liquid nitrogen as a means of cooling and improvements in mechanical properties were reported in previous studies, such as $[16,18,19,27-31]$. These studies describe that similarly to the cryogenic treatment performed at the samples surfaces, where the material is cooled to around $-80^{\circ} \mathrm{C}(\mathrm{CT})$, ULTP involves the transformation of retained austenite into martensite [27-30]. They showed that deep cryotreating induces significant modifications in the precipitation behavior of secondary carbides, which combined with the marked reduction in the retained austenite content improve the tribological properties of the matrix. It can be said that the formation and distribution of secondary carbides are the main mechanisms controlling the tribological and mechanical behavior of tool steels. Das et al. [30] showed that in the D2 steel cold work, there was an increase in the formation of refined secondary carbides, a higher volume fraction and more evenly distributed in cryogenically treated samples (ULTP) compared to those treated conventionally. One of the hypotheses for the appearance of these carbides would be the fact that the cooling can cause an iron crystalline network deformation due to the contraction of the steel in low temperature $[18,19]$. Thus the carbon atoms would be forced out of their original positions in the iron interstitial tetragonal lattice, an order to offset the distance between atomic planes, generating the formation of finely dispersed carbides of transition and evenly distributed ( $\eta$-carbide) $[18,19]$. Sonar et al. [16] indicate that with deep cryogenic treatment in AISI D2 steel there is minimal dimensional deviation when compared to conventional heat treatment. For the M2 tool steel, Huang et al. [31] observed a higher volume fraction and a more homogeneous distribution of carbides in cryogenically treated samples (TCP) compared to samples treated with conventional treatment.

Recently according to Cozza et al.. [32, 33] and Krelling et al. [34], the microscale abrasive wear test has gained wide acceptance in universities and research centers and is widely used in studies of abrasive wear of materials. However, investigations of micro-scale abrasive wear on ULTP thermally treated tool steels have not been explored or characterized. The main objective of the present research was to investigate the effect of deep cryogenic treatment (ULTP) on micro-scale abrasive wear resistance. For that, tests of wear were carried out by microabrasion, evaluating the loss of mass of the specimens by a system of laser interferometry. In addition, conventional microhardness, optical microscopy and scanning electron microscopy (SEM) techniques were applied to the characterization of the treated samples. And for the quantification of fine carbides obtained in the samples through the images of SEM was used image analyzer software.

\section{Materials and Methods}

\subsection{Materials}

AISI D2 cylindrical tool steel samples with dimensions of $16 \times 10 \mathrm{~mm}$ (diameter and length, respectively) were used. Table 1 shows the chemical composition determined by mass spectroscopy. Figure 1 shows the initial microstructure of the samples in the annealed condition, composed of globular carbides distributed in a ferritic matrix. The initial microstructure of AISI D2 for heat treatment is usually the annealed condition, with the matrix composed of ferrite containing globular carbides [27].

Table 1. Chemical composition (\% in mass) of AISI D2 steel.

\begin{tabular}{ccccccccccc}
\hline Element & $\mathbf{C}$ & $\mathbf{M n}$ & $\mathbf{S i}$ & $\mathbf{P}$ & $\mathbf{S}$ & $\mathbf{C r}$ & $\mathbf{V}$ & $\mathbf{M o}$ & $\mathbf{N i}$ & $\mathbf{F e}$ \\
\hline $\mathrm{Wt}(\%)$ & 1.49 & 0.35 & 0.42 & 0.023 & 0.003 & 12.04 & 0.68 & 0.64 & 0.18 & Balance \\
\hline
\end{tabular}




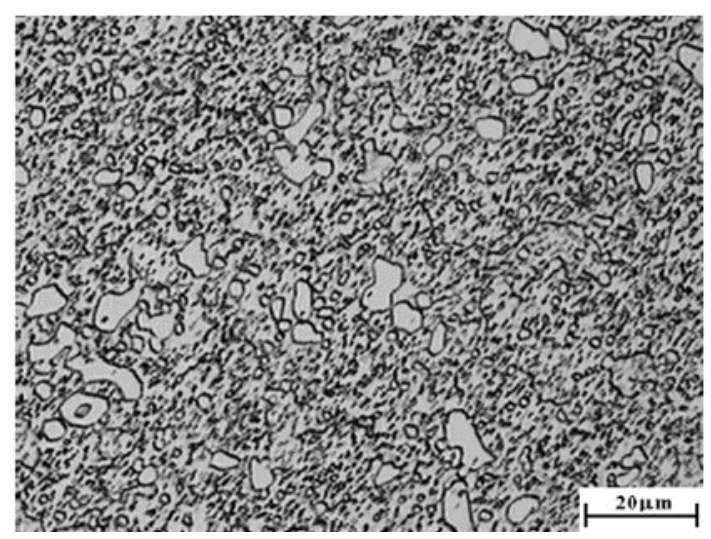

Figure 1. AISI D2 Steel Microstructure. Initial state in annealed condition. Ferritic matrix with dispersed globular carbides. Nital etching reagent. Optical microscope.

\subsection{Thermal Treatment}

Three cycles of heat treatment with different combinations between tempering and ULTP, called QTT, QUTT and QTUT, were performed. The QTT condition is a conventional double-tempered treatment. In the QUTT the cryogenic treatment was carried out with a subsequent double tempering. And in the QTUT condition the cryogenic treatment was inserted between the tempering (as outlined in Figure 2a). The annealing time was $1 \mathrm{~h} 30 \mathrm{~m}$ at $510^{\circ} \mathrm{C}$.

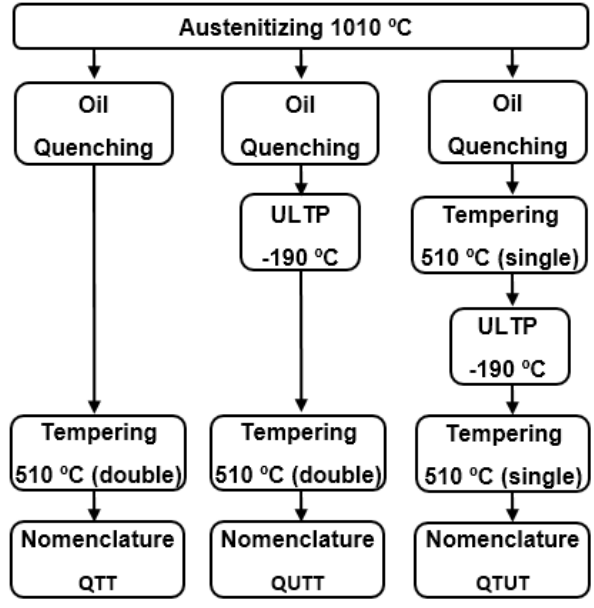

(a)

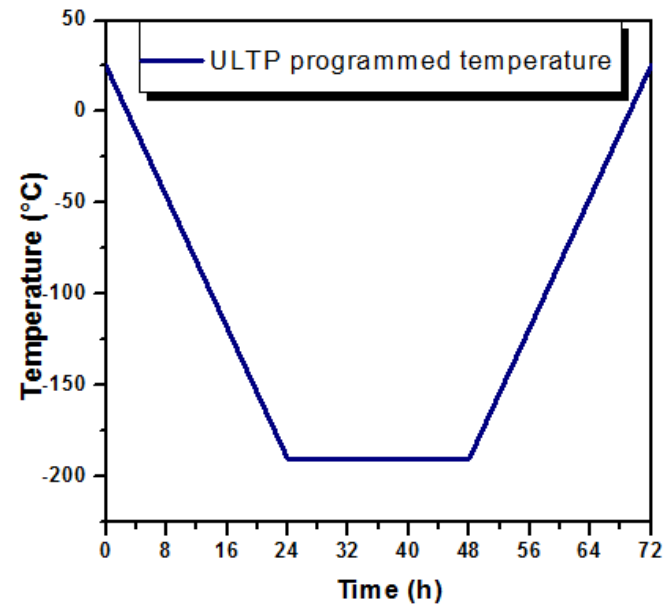

(b)

Figure 2: (a) Heat Treatment cycles applied on the samples; (b) Theoretical curve of the deep cryogenic treatment cycle.

The ULTP treatment was performed by Kryos Cryogenic Engineering, Brazil, using liquid nitrogen as a coolant. The treatment cycle last $72 \mathrm{~h}$ total, being $24 \mathrm{~h}$ in constant cooling rate, $24 \mathrm{~h}$ in flooding temperature with constant temperature $\left(-190^{\circ} \mathrm{C}\right)$ and $24 \mathrm{~h}$ with constant rate of heating. The graph of Figure $2 \mathrm{~b}$ shows the theoretical temperature curve during treatment. The theoretical programmed rates of cooling and heating are approximately $-0.14{ }^{\circ} \mathrm{C} / \mathrm{min}$ and $0.14{ }^{\circ} \mathrm{C} / \mathrm{min}$. Before the liquid nitrogen was induced in the chamber, it is evaporated to enable controlled cooling and to prevent a severe gradient of temperature between the surface and the core of the specimens $C$ [35].

$X$-ray diffraction was performed with $\mathrm{CuK} \alpha$ radiation, in the range $30^{\circ} \leq 2 \theta \leq 90^{\circ}$, with an angular cross-section of 0.05 . After sanding and polishing, the samples were etched with $4 \%$ Nital reagent. The metallographic examinations were performed with conventional optical microscope and scanning electron microscope (SEM). Quantitative carbide analyses were performed with Scion Image (Scion Corporation). Vickers microhardness assay were conducted under all thermal calorie-processing conditions used. 


\subsection{Micraoabrasive Wear}

The abrasive wear tests were performed on free ball micro-abrasion equipment (Calowear, CSM instruments). Samples with and without ULTP treatment were subjected to three tests each and 12 different slip distances. The reconstruction and measurement of the wear crater diameter generated in the tests was performed by Laser Interferometry.

Table 2 shows the test conditions selected for the experiments conducted in this work. An AISI 52100 steel ball with a diameter of $25.4 \mathrm{~mm}$ was used. The abrasive was a slurry comprised of abrasive particles of silicon dioxide $\left(\mathrm{SiO}_{2}\right)$ suspended in distilled water, at a concentration of $0.75 \mathrm{~g}$ of abrasive per $\mathrm{cm} 3$ of water. The granulometric distribution of the abrasive particles was between $0.5-10 \mu \mathrm{m}$, with approximately $80 \%$ between $1-5 \mu \mathrm{m}$. The abrasive slurry was continuously agitated to prevent decanting of the abrasive particles and pumped to the sphere-sample interface using a peristaltic pump. The flow rate of the abrasive was set at about one drop every 3 seconds. Rotation of the drive shaft was maintained at $150 \mathrm{rpm}$, generating a velocity between the ball surface and the sample of approximately $0.109 \mathrm{~m} \cdot \mathrm{s}^{-1}$. The standard assay load was $0.33 \mathrm{~N}$.

The distance (S) was identified by an expression (1). The emission volume was sent to each displacement time interval using an equation (2) [32-34, 36-38] for $b \ll \phi$. The wear coefficient - K was calculated through Archard's law (3) [32-34, 36-38]. Where $n_{2}$ it is the numbers of turns performed by the drive shaft of the equipment test; $\phi$ the diameter of the test ball, $b$ the diameter of the wear cap and $\mathrm{N}$ is the normal force of the test.

$$
\begin{gathered}
S=\frac{19,95 n_{2} \phi}{\sqrt{\frac{\phi^{2}}{4}-25}}, \\
V \cong \frac{\pi \cdot b^{4}}{32 . \phi} \\
k=\frac{\pi \cdot b^{4}}{32 \cdot \phi \cdot S \cdot N}
\end{gathered}
$$

Table 2. Test conditions for the micro abrasive wear experiments.

\begin{tabular}{ccccccccccccc}
\hline $\begin{array}{c}\text { Test } \\
\text { condition: }\end{array}$ & $\mathbf{1}$ & $\mathbf{2}$ & $\mathbf{3}$ & $\mathbf{4}$ & $\mathbf{5}$ & $\mathbf{6}$ & $\mathbf{7}$ & $\mathbf{8}$ & $\mathbf{9}$ & $\mathbf{1 0}$ & $\mathbf{1 1}$ & $\mathbf{1 2}$ \\
\hline $\begin{array}{c}\text { Normal } \\
\text { force-N (N) }\end{array}$ & 0,33 & 0,33 & 0,33 & 0,33 & 0,33 & 0,33 & 0,33 & 0,33 & 0,33 & 0,33 & 0,33 & 0,33 \\
\hline $\begin{array}{c}\text { Sliding } \\
\text { distance-S (m) }\end{array}$ & 32,55 & 65,11 & 97,66 & 130,21 & 162,76 & 195,32 & 227,87 & 260,42 & 292,97 & 325,53 & 358,08 & 390,63 \\
\hline $\begin{array}{c}\text { Ball rotational } \\
\text { speed-(rpm) }\end{array}$ & 81,59 & 81,59 & 81,59 & 81,59 & 81,59 & 81,59 & 81,59 & 81,59 & 81,59 & 81,59 & 81,59 & 81,59 \\
\hline $\begin{array}{c}\text { Tangential } \\
\text { sliding } \\
\text { velocity-(m/s) }\end{array}$ & 0,109 & 0,109 & 0,109 & 0,109 & 0,109 & 0,109 & 0,109 & 0,109 & 0,109 & 0,109 & 0,109 & 0,109 \\
\hline $\begin{array}{c}\text { Test time } \\
\text { (min) }\end{array}$ & 5 & 10 & 15 & 20 & 25 & 30 & 35 & 40 & 45 & 50 & 55 & 60 \\
\hline $\begin{array}{c}\text { Number of } \\
\text { repetitions }\end{array}$ & 3 & 3 & 3 & 3 & 3 & 3 & 3 & 3 & 3 & 3 & 3 & 3 \\
\hline
\end{tabular}

\section{Results}

\subsection{Microstructural Analysis}

The results of microstructural analysis, by optical microscopy, after the different cycles of thermal treatments are shown in Figure 3. The microstructure corresponds to the martensite with dispersed carbides. Through this characterization technique it is not possible to visualize differences 
between the different paths or cycles of heat treatment applied, that is, between the samples treated and those not treated cryogenically.

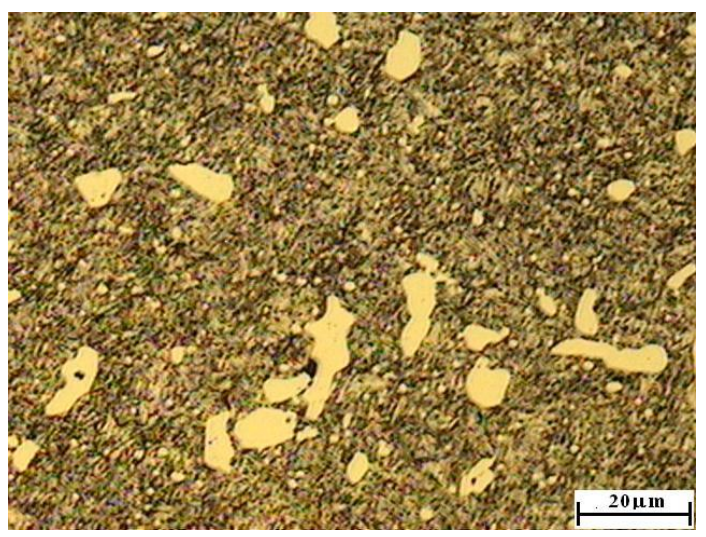

(a)

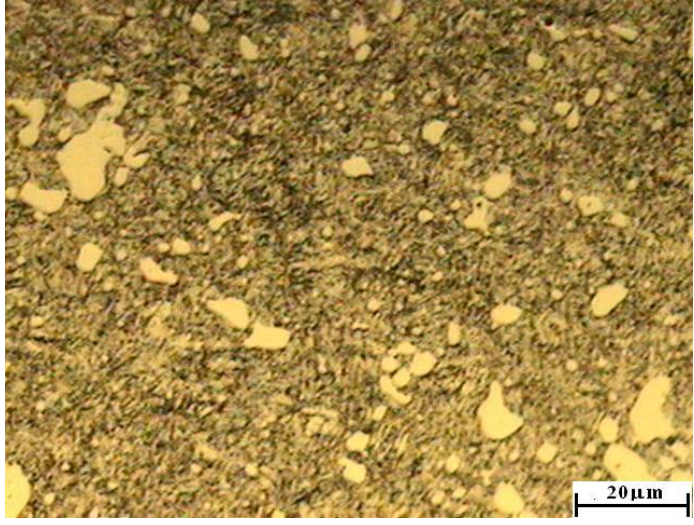

(b)

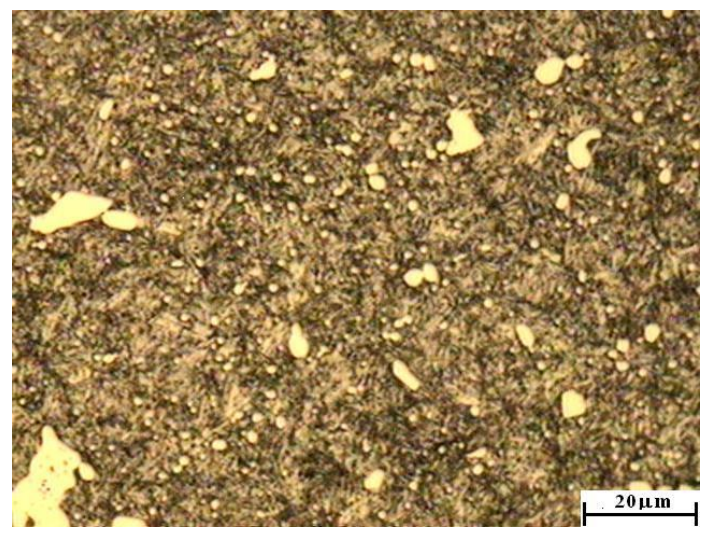

(c)

Figure 3: AISI D2 Steel tool microstructure2: (a) case QTT; (b) case QUTT; (c) case QTUT. Martensitic matrix with dispersed carbides. $4 \%$ Nital etching reagent. Optical microscope. 500x.

In Figure 4 the micrographs obtained by scanning electron microscopy (SEM) of the AISI D2 steel samples treated according to the three cycles of thermal treatments are shown. It is possible to observe a microstructure composed by the presence of carbides dispersed in martensitic matrix. Also, eutectic carbides or primary carbides can be visualized (as shown in Fig 4a). The distribution of the carbides in the matrix was carried out with specific programs, as described in the following items. 


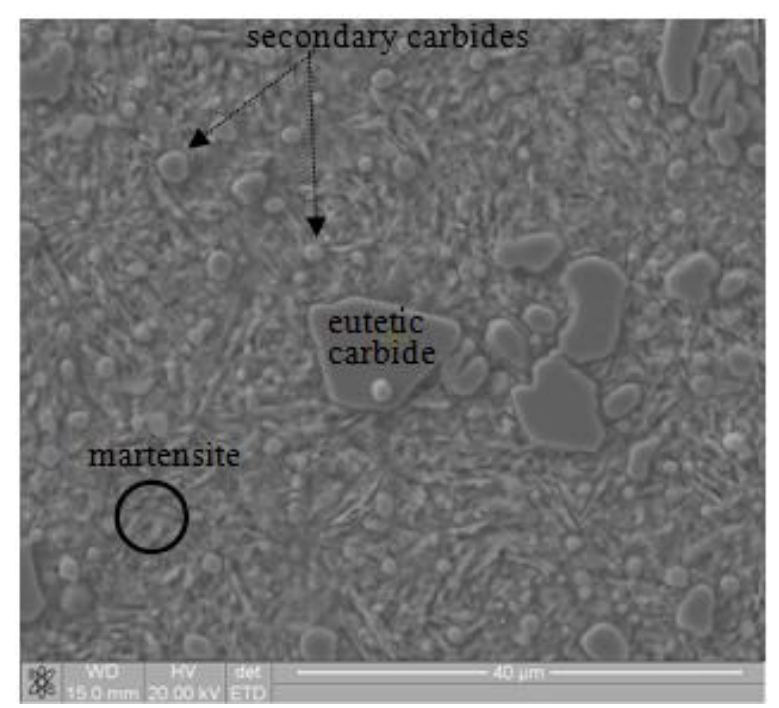

(a)

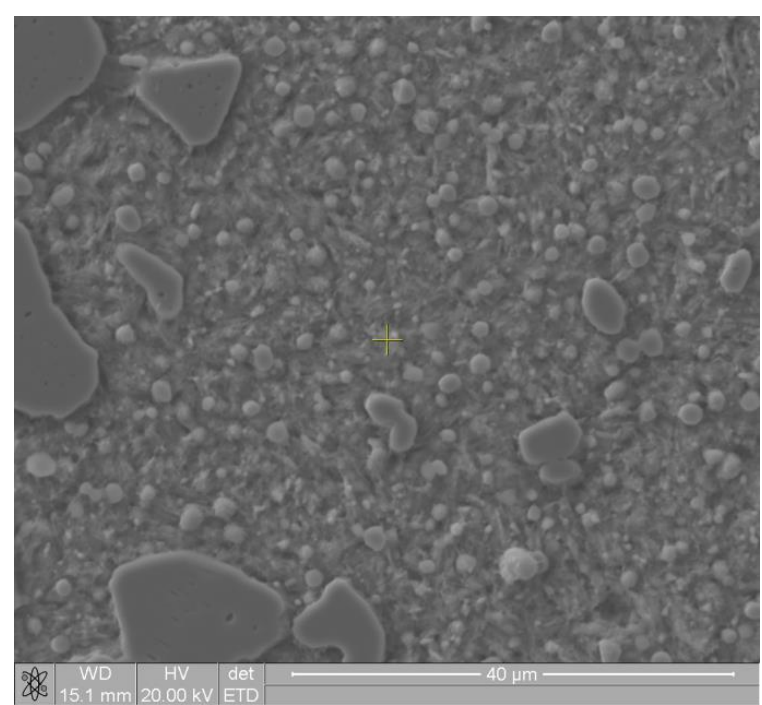

(b)

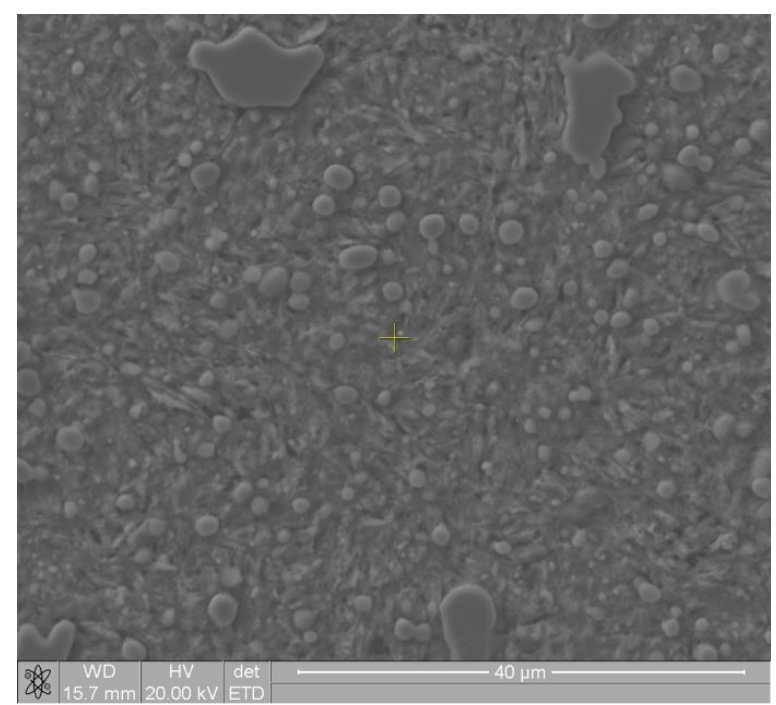

(c)

Figure 4: Microstructure using SEM in the thermal cases: (a) QTT, (b) QUTT, (c) QTUT. Eutectic carbide and martensite. $4 \%$ Nital etching reagent.

\subsection{Vickers Microhardness Tests}

Figure 5 presents the microhardness results for the treated and non-cryogenically treated samples, according to the conditions cycle outlined in Figure 1. The conventional heat treatment, called QTT, whose average microhardness was $661.5 \mathrm{HV} 0.3$, was used as reference. Microhardness results were obtained for cryogenic samples (QUTT and QTUT conditions). For the samples of the QTUT group, which presented a cryogenic treatment step between the annealing cycles, a microhardness increase of $0.94 \%$ (667.8 HV0.3) was obtained. The QUTT treatment, which presented a cryogenic treatment step before double tempering, provided a higher microhardness increase over the QTT reference condition, of 4.7\% (692.8 HV0.3).

The hardness values for the samples submitted to different heat treatment schemes can be directly related to the magnitude of the reduction of the retained austenite softness and to the improvement in the amount of hard and fine secondary carbides dispersed in the martensitic matrix (figure 6). Several papers report an increase in the hardness of tool steels with deep cryogenic treatment, such as $[8,14,15,25,39-43]$. An increase of approximately $7 \%$ in the microhardness of the A2 tool steel due to the deep cryogenic treatment over the conventional heat treatment is reported by 
Zurecki [39]. Çiçek et al. [14] showed an improvement in the macro (HRC) - and micro (HV0,2) hardness of the cryogenically treated AISI H13 tool steel. Dixit et al. [40] in the study of the cryogenically treated steel tool D5 show improvements of approximately $5-10 \%$ over the conventional heat treatment. They report that the hardness values for multiple curing after cryogenic treatment were decreased compared to a single tempering. Increasing hardness by cryogenic treatment compared to conventional treatment between $1.6 \%$ and $3.1 \%$ for 4340 steel was reported by Zhirafar et al. [25], between 9-12\% for 45WCrV7 tool steel [42]. For AISI M2 and H13 tool steels the ultra-low temperature treatment increased the hardness compared to the conventional heat treatment by $5.8 \%$ and $3.0 \%$, respectively [8]. An improvement of $4.1 \%$ due to the cryogenic treatment over the conventional $18 \mathrm{NiCrMo5}$ steel [43]. Çakir and Çelik [15] performed cryogenic treatment after tempering and prior to tempering for eutectoid steel, describing a slight increase in the hardness of the samples and as the cryogenic treatment time increases (for $36 \mathrm{~h}$ ) the hardness increases slightly.

The two ULTP treatment cycles performed on the samples improve the microhardness of the tool steel matrix under study (figure 5). However, the degree of improvement by ULTP when performed immediately after quenching and before double tempering is higher $(4.7 \%)$. The nucleation of fine carbides ( $\eta$-carbides) occurring during ULTP after quenching may represent the basis for the growth of secondary carbides after ULTP. The cryogenic treatment causes martensite network distortion due to the increase in volume, while it is transforming most of the austenite into martensite [14, 15]. Dislocations occur and, depending on these distortions, generate new nucleation sites for the precipitation of small carbides during the tempering process after cryogenic treatment; this volumetric expansion, caused by the cryogenic treatment, creates a compression force at the carbide-matrix interface and this force prevents the delamination between the carbide and the matrix [14]. Clustering of interstitial carbon at cryogenic temperature (liquid nitrogen $-196^{\circ} \mathrm{C}$ ) was confirmed by Barbé et al. [44] when they studied austenite metastable in low alloy steel FeCMnSi TRIP. When the low temperature treatment is applied after the first tempering, the amount of retained austenite that is converted to martensite during the cryogenic treatment [15] may be considerably smaller than expected, since part of the retained austenite may have been stabilized by pre-cryogenic treatment [45]. Collins [10] reports that the higher the amount of retained transformed austenite the greater the difference in hardness caused by the cryogenic treatment; and the formation of fine carbides, which are attributed to the deep cryogenic treatment, results in increased wear resistance and toughness of the material, but little or no effect on the hardness.

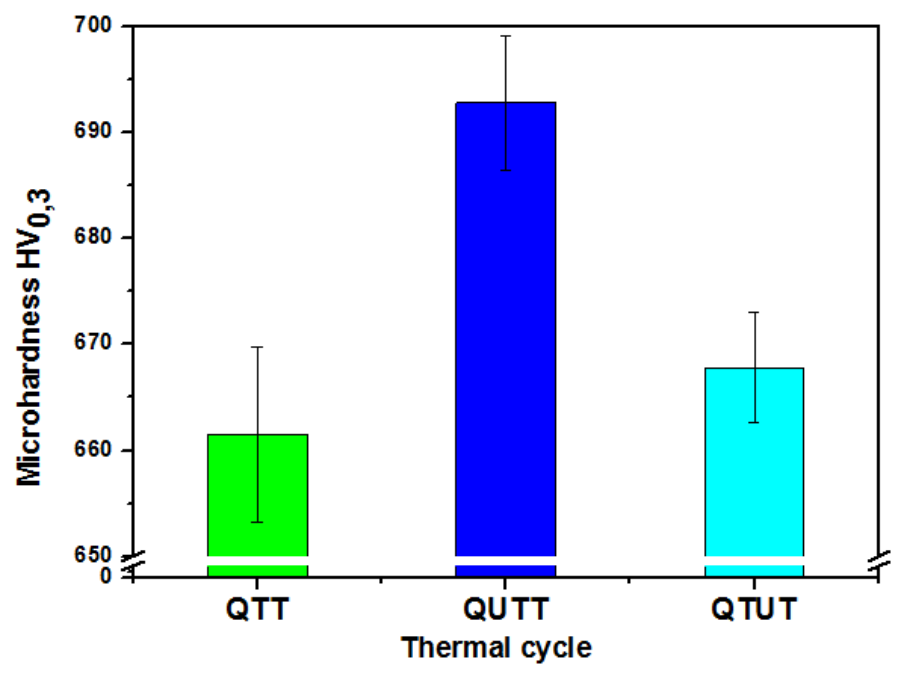

Figure 5. Results from Vickers micro hardness tests to the AISI D2 samples.

\subsection{Carbide Image Analysis}

By electron microscopy, obtained by SEM, carbide quantification was performed using Scion Image software. The results were excluded using Image J. software. 
Figure 6 shows the results of the carbide count obtained from the samples in the different treatment cycles. The introduction of deep cryogenic treatment has shown to promote an increase in the amount of small carbides precipitated in the steel, as observed for QUTT and QTUT samples in relation to QTT reference samples.

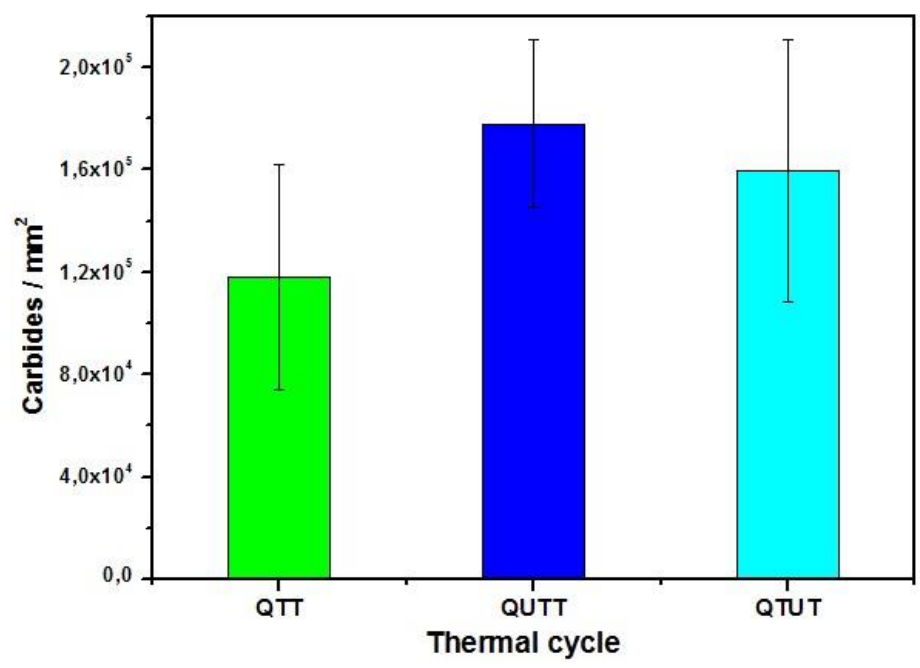

Figure 6: Carbides $/ \mathrm{mm}^{2}$ count for different heat treatments cycles.

The heat treatment schedule corresponding to the QUTT condition, which shows the cryogenic treatment step after the quenching process, showed a larger increase in the amount of precipitated carbides in relation to the QTT reference condition. Similarly, for the heat treatment referring to the QTUT condition, which has a tempering step before and after the cryogen treatment, it is found that the amount of carbides is higher than the QTT reference condition, however in a relatively minor proportion when compared the condition QUTT (ULTP performed after quenching). This lower effectiveness of the treatment cycle of the QTUT condition is possibly related to the fact that a tempering step in the material before the cryogenic treatment decreases martensite supersaturation. During the cooling in the cryogenic temperature the volume contraction of the martensite cell occurs and it becomes more thermodynamically unstable [29].

As in the samples in the QTUT condition the martensite is already in a less supersaturated state by the tempering stage prior to the ULTP, it is expected that during the cryogenic treatment its instability will be lower, resulting in a lower precipitation of fine carbides, which seems to be in agreement with the data obtained (figure 7).

Also, as reported by Popandopulo and Zhukova [17], Meng et al. [18], Yen and Kamody [19], Yun et al. [29], a greater effect of the cryogenic treatment was observed in the precipitation of fine carbides when it is carried out in a tool steel with martensitic structure in the condition only tempered and before tempering. The transformation of martensite into high carbon steels is accompanied by plastic deformation of virgin martensite, which is a physical reason for the beneficial effect of ULTP on tool steels [28]. An important consequence of plastic deformation is the capture of carbon atoms and formation of carbon clusters, which can serve as sites for nucleation of fine n-carbide particles during the subsequent tempering step [28].

By subjecting the samples at low temperature is generated high-density crystal defects such as dislocations/dislocation and mackles into martensite during the cooling cycle cryogenic processing, since high internal stresses are developed from the continuous transformation of austenite to martensite and of differential thermal contractions of the phases. The martensite thus becomes more supersaturated with decreasing temperature, and this phenomenon, in turn, increases its distortion of the lattice parameters and thermodynamic instability resulting in the segregation of carbon atoms to close defects forming agglomerates or clusters. These agglomerates act as or grow in cores for the formation of secondary carbide in subsequent heating or during tempering [30]. Thus, ULTP effectively increases the decomposition of martensite which, in turn, leads to a greater amount of 
refined secondary carbides in samples of ULTP treated compared to conventional treatment samples, as observed in the present study.

\subsection{X-Ray Diffractometry}

Analysis of X-ray diffractometry indicates existing $\mathrm{M}_{7} \mathrm{C}_{3}$ and tempered martensite $(\mathrm{Fe}-\alpha)$. As observed in Figure 7, where is a superposition of all spectrum, the peaks of $\alpha$ phase and $\mathrm{M}_{7} \mathrm{C}_{3}$ phase can be seen at the same incident angles for all treatment cycles. Therefore, all standard shows the same diffraction peaks.

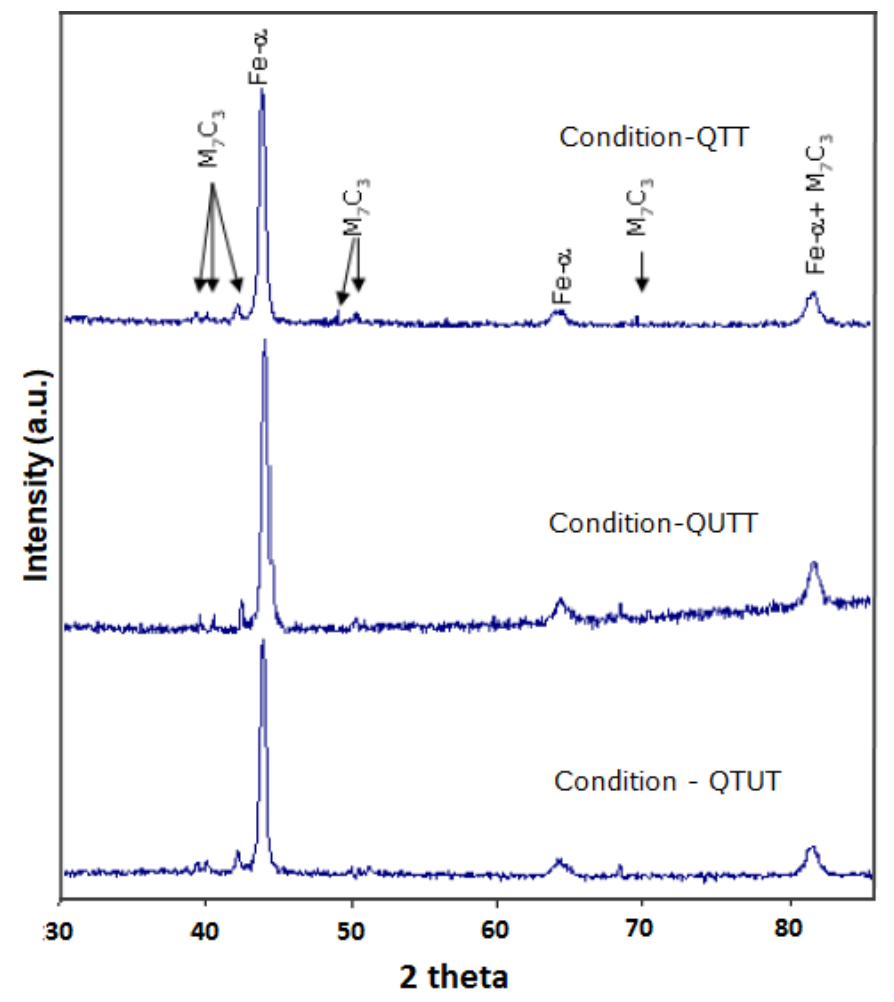

Figure 7. X-Ray diffractometry analysis.

\subsection{Microabrasion Wear Test}

In order to perform micro abrasive wear tests, it is first necessary to determine or obtain the condition of permanent wear regime [36-38]. For this purpose, the wear coefficient $\mathrm{k}$ was plotted against the test time $\mathrm{t}$, that is, $k=f(t)$, checked the condition of stability $k$ when it remains constant with the variation of the test time $(t)$. In this work, the wear rate $k$ was found to have reached stability only after a traversing distance of approximately 227 meters (35 minutes) of the test (Figure 8). This minimum slip distance was verified and considered for all treatment conditions (samples QTT, QUTT and QTUT). 


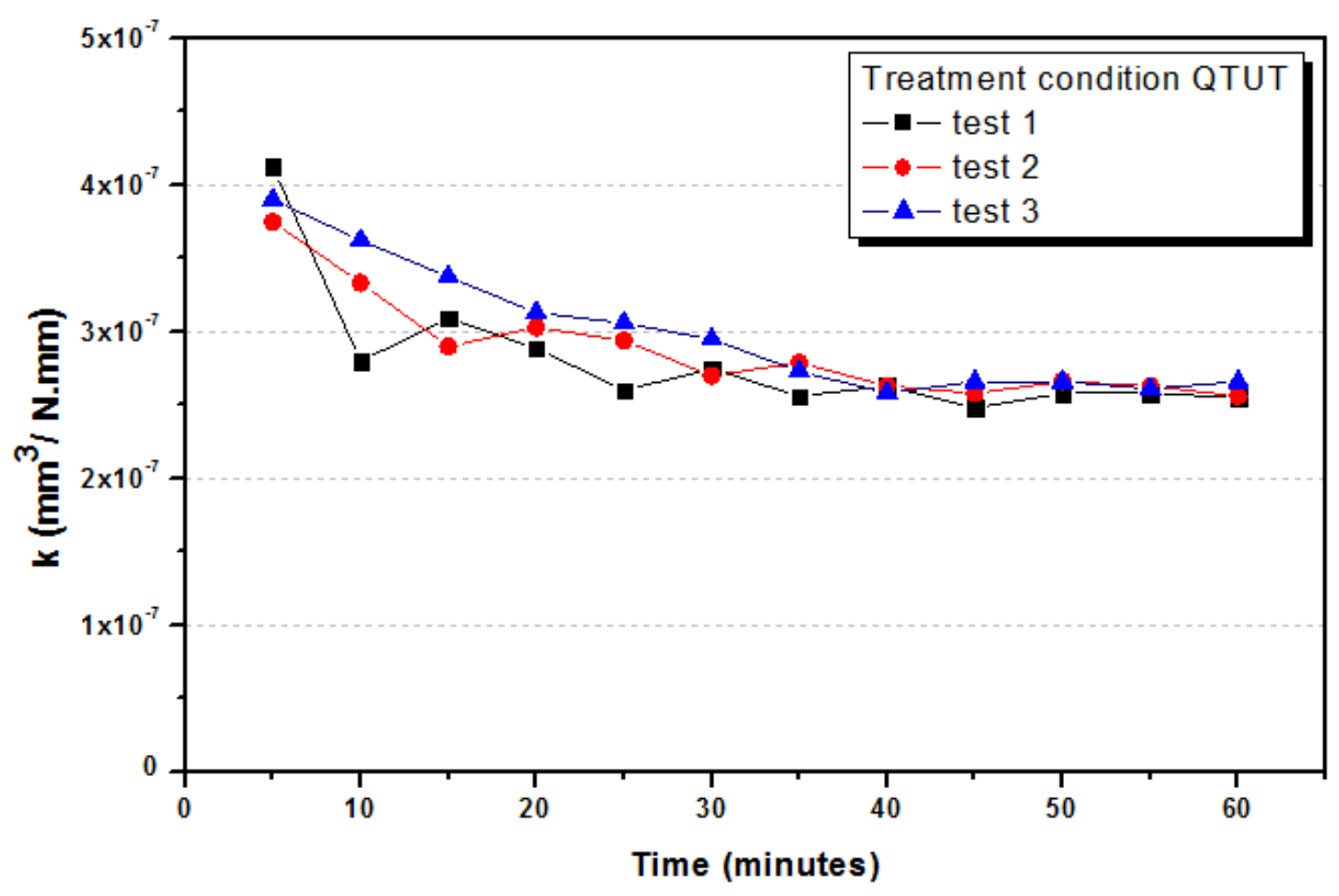

Figure 8. Wear coefficient as function of the time test, showing the permanent wear regime reach. Case QTUT.

The shape of the wear calotte produced on the samples can significantly influence the coefficient of wear. In order to show that the topography of the calotte follows the shape of the sphere, measurements were made that are presented in Figure 9 through laser interferometry. Therefore, the profiles of the wear caps (material removed from the sample) generated during the test were extracted (Figure 9). In the case of spherical shells in the same curvature of the sphere of the micro abrasive wear test, it is possible to use basic equations mentioned in the methodology for the calculation of the worn volume and the coefficient of wear $k$ [33, 36-38]. Through laser interferometry the effect of scuffing [38,46] was significantly reduced, with a clear and clear identification of the border of the calottes (Figure 9). Scuffing s regarded as the region around the edge of the crater wear that although harshly or rough and scratched is flat [38] and may cause difficulties in determining the real edge of the calotte [46]. 

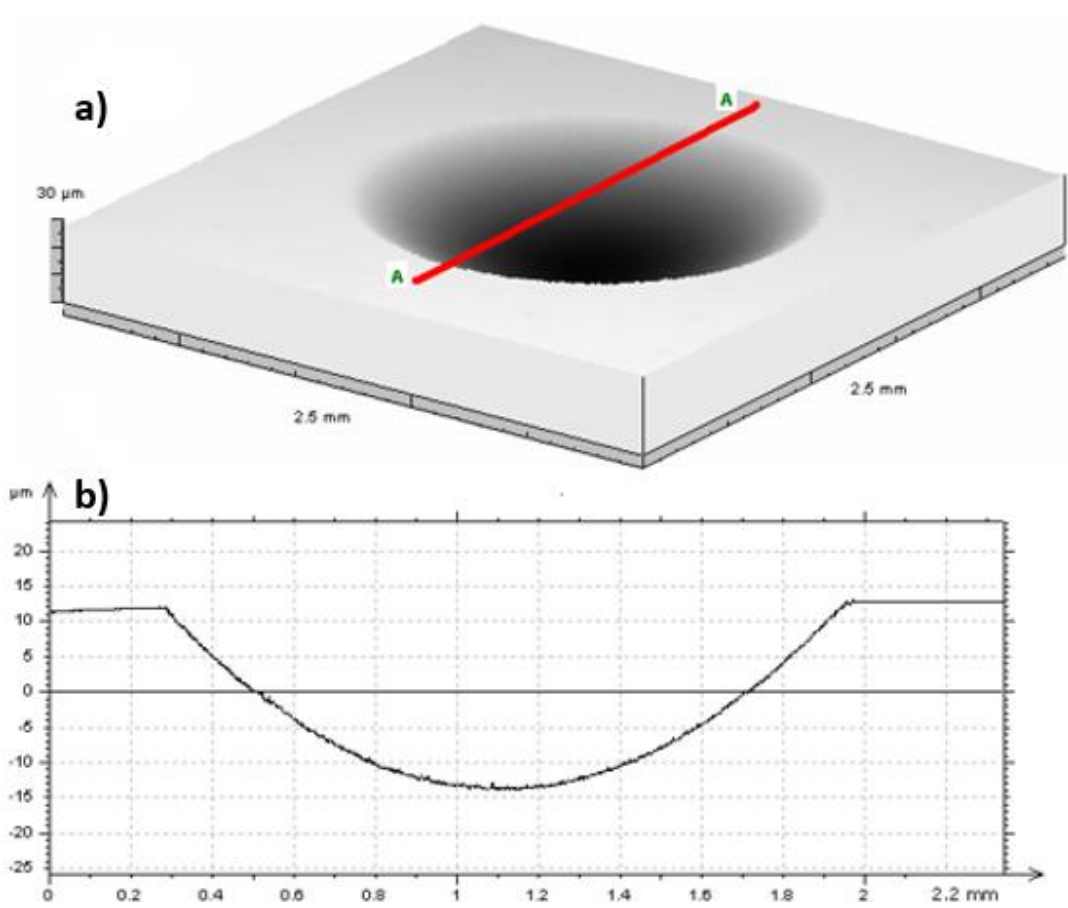

Figure 9. Typical aspect for the craters obtained by laser interferometry. (a) 3D surface. (b) Profile trace of the crater of the AA dash. Treatment cycle C. Data obtaining mode for determination of worn volume $\mathrm{V}$ and wear coefficient $\mathrm{K}$.

Figure 10 shows the behavior of the wear coefficient $\mathrm{k}$ in the samples submitted to the three different cycles of thermal treatment. This value of the wear coefficient $\mathrm{k}$ for each treatment condition was determined by the average of the three tests for each test time and for the slip distances that are above $227.87 \mathrm{~m}$ (considering the reach of the permanent regime).

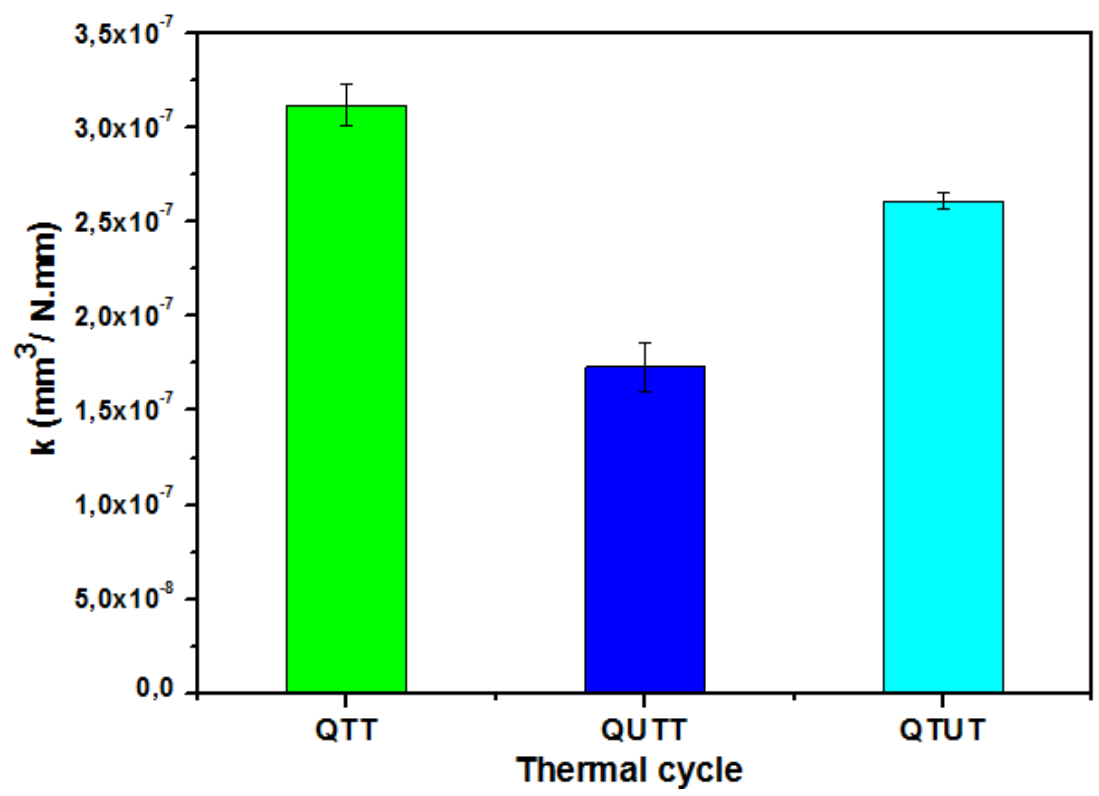

Figure 10. Results of the wear coefficient $\mathrm{k}$ for the different heat treatment cycles.

The results of the micro-abrasion wear test on the AISI D2 tool steel allowed the evaluation of the effect of the different cycles of thermal treatments, especially the ULTP stage, on the wear resistance of this material. It can be observed that the cryogenically treated samples showed less wear when compared to samples with conventional heat treatment. In the QTUT condition there is a moderate increase in the wear resistance, with a wear coefficient decrease of $16.3 \%$ in relation to the QTT condition. However, in the QUTT condition there is a greater decrease in the amount of 
material removed in the test, resulting in a wear coefficient of $44.5 \%$ less than the QTT condition. The deep cryogenic treatment introduction with posterior tempering indicates that it is responsible for the improvement in the micro abrasive wear resistance of AISI D2 steel, especially when the supercooling is performed immediately after quenching as in the case of the QUTT samples. There is a direct correlation between the results of the wear resistance with the measured results of the hardness of the samples and analyzing the quantification of carbides. The large reduction in wear rate may be mainly due to the transformation of retained austenite to martensite, the homogenate carbide distribution and fine carbide precipitation due to the ULTP. In the case of samples B, with ULTP immediately after quenching and followed by double tempering, the greatest reduction in the coefficient of wear may be due to a greater transformation of retained austenite in martensite, in the distribution of homogenized carbide and in the amount of precipitation of carbides thin films compared to treatment cycle $C$ with a tempering step prior to annealing and prior to ULTP, as discussed previously in microhardness results and carbide image analysis.

The fine and uniformly distributed dispersion of the $\eta$-carbide particles are considered the main reasons for the significant improvement in the abrasive wear resistance of the high carbon tool steels as a result of the deep cryogen treatment (ULTP) [28]. A significant increase in wear resistance is also shown by Barron [13] for different types of tool steels and stainless steels. However, in the case of the cold working steel D2 the improvements in wear resistance cited in the literature may range from about $10 \%$ [12] to $800 \%$ [13]. The present work proposes to investigate the effects of the ULTP on the abrasive wear in micro-scale in the samples of AISI D2 steel, showing a reduction in the coefficient of wear of up to $44.5 \%$ in relation to the conventional thermal treatment.

\section{Conclusions}

Samples of AISI D2 tool steel austenitized at the conventional annealing temperature $\left(1010{ }^{\circ} \mathrm{C}\right)$ and tempering $\left(510^{\circ} \mathrm{C}\right)$ reacted positively to the deep cryogenic treatment $\left(-190^{\circ} \mathrm{C}\right)$ with a significant improvement in micro-scale abrasive wear resistance.

ULTP treatments on the samples are most effective when applied shortly after quenching. Tempering step in the material before deep cryogenic treatment decreases martensite supersaturation, with possible stabilization of retained austenite and with lower carbon capture and formation of carbon clusters, which are $\eta$-carbide nucleation sites.

There was a reduction of the wear coefficient $\mathrm{k}$ of the order of $44.5 \%$ for the treatment cycle of the QUTT condition and $16.3 \%$ for the treatment cycle of the QTUT condition in relation to the treatment cycle without the ULTP step (QTT condition).

This wear resistance increase is related to the transformation of retained austenite in martensite and the increase in the amount of precipitated carbides with the cryogenic deep treatment - ULTP.

Author Contributions: conceptualization, J.V.G., S.J.G. and G.R.; methodology, S.J.G. and J.V.G.; validation, J.V.G., S.J.G. and G.R.; formal analysis, J.V.G., S.J.G. and G.R.; investigation, J.V.G. and S.J.G..; writing-review and editing, J.V.G., S.J.G. and G.R; supervision, S.J.G.

Funding: This research received no external funding.

Conflicts of Interest: The authors declare no conflict of interest.

\section{References}

1. Toboła, D.; Brostow, W.; Czechowski, K.; Rusek, P. Improvement of wear resistance of some cold working tool steels. Wear 2017, 382-383, 29-39.

2. Podgornik, B.; Paulin, I.; Zajec, B.; Jacobson, S.; Leskov`sek, V. Deep cryogenic treatment of tool steels. Journal of Materials Processing Technology 2016, 229, 398-406.

3. Gåård, A. Wear in Sheet Metal Forming. Phd Thesis. Karlstad University Studies, Karlstad, 2008.

4. Korade, D.N.; Ramana, K.V.; Jagtap, K.R.; Dhokey, N.B. Effect of Deep Cryogenic Treatment on Tribological Behaviour of D2 Tool Steel - An Experimental Investigation. Materials Today: Proceedings 2017, 4, 7665-7673.

5. Yasavol, N.; Ramalho, A. Wear properties of friction stir processed AISI D2 tool steel. TribologyInternational 2015, 91, 177-183. 
6. Song, R.G.; Zhang, K.; Chen, G.N. Electron beam surface remelting of AISI D2 cold- worked die steel. Surface and Coatings Technology 2002; 157, 21-4.

7. Bourithis, L.; Papadimitriou, G.D.; Sideris, J. Comparison of wear properties of tool steels AISI D2 and O1 with the same hardness. Tribology International 2006, 39, 479-489.

8. Molinari, A.; Pellizzari, M.; Gialanella, S.; Straffelini, G.; Stiasny, K.H. Effect of deep cryogenic treatment on the mechanical properties of tool steels. Journal of Materials Processing Technology 2001, 118, 350355.

9. Barron, R.F.; Mulhern, C.R. Cryogenic treatment of AISI T8 and C1045 steels. Advances in Cryogenic Engineering Materials 1980, 26, 171-179.

10. Collins, D. N. Deep Cryogenic Treatment of tool steels: a rewiew. Heat Treatment of Metals 1996, $23,40-42$.

11. Da Silva, F.J.; Franco, S.D.; Machado, A.R.; Emanuel, O.E.; Souza Jr., A.M. Performance of cryogenically treated HSS tools. Wear 2006, 261, 674-685.

12. Collins D. N., Cryogenic treatment of tool steels. In: Advance Materials and Processes 1998,154, H23-H29.

13. R. F. Barron. Cryogenic treatment of metals to improve wear resistance. Cryogenics 1982, 22, 409-413.

14. Çiçek, A.; Kara, F.; Kivak, T.; Ekici, E.; Uygur, I. Effects of Deep Cryogenic Treatment on the Wear Resistance and Mechanical Properties of AISI H13 Hot-Work Tool Steel. Journal of Materials Engineering and Performance 2015, 24, 4431-4439.

15. Çakir, F.H.; Çelik, O.N. The effects of cryogenic treatment on the toughness and tribological behaviors of eutectoid steel. Journal of Mechanical Science and Technology 2017, 31, 3233-3239.

16. Sonar, T.; Lomte, S.; Gogte, C.; Balasubramanian, V. Minimization of distortion in heat treated AISI D2 tool steel: mechanism and distortion analysis. 2nd International Conference on Materials Manufacturing and Design Engineering 2018, 20, 113-118.

17. Popandopulo, A.N.; Zhukova, L.T. Transformations in high speed steels during cold treatment. Metal Science and Heat Treatment 1980, 22, 708-710.

18. Meng, F.; Tagashira, K.; Azuma, R.; Sohma, H. Role of eta-carbide precipitations in the wear resistance improvements of Fe-12Cr-Mo-V-1,4C tool steel by cryogenic treatment. ISIJ International 1994, 34, 205-210.

19. Yen, P.L.; Kamody, D.J. Formation of fine eta carbide in special cryogenic and tempering process key to improve properties of alloy steels. Industrial Heating 1997, 64, 40-44.

20. Surberg, C.H.; Stratton, P.; Lingenhöle, K. The effect of some heat treatment parameters on the dimensional stability of AISI D2. Cryogenics 2008, 48, 42-47.

21. Lal, D.M.; Renganarayanan, S.; kalanidhi, A. Cryogenic treatment to augment wear resistance of tool and die steels. Cryogenics 2001, 41, 149-155.

22. Yong, A.Y.L.; Seah, K.H.W.; Rahman, M. Performance evaluation of cryogenically treated tungsten carbide tools in turning. International Journal of Machine Tools and Manufacture 2006, 46, 2051-2056.

23. Stratton, P.F. Optimising nano-carbide precipitation in tool steels. Material Science and Engineering: A 2007, 449-451, 809-812.

24. Roberts, G.; Krauss,G.; Kennedy, R. Tool Steels. 5th ed., ASM International, Metals Park, OH, USA, 1998.

25. Zhirafar, S.; Rezaeian, A.; Pugh, M. Effect of cryogenic treatment on the mechanical properties of 4340 steel 2007, 186, 298-303.

26. Carlson, E.A. ASM Handbook. v.4, Heat Treating, 10th ed., ASM International, Metals Park, Ohio, 1990.

27. Farina, P.F.S.; Farina, A.B.; Barbosa,C.A.; Goldenstein, H. Effects of cryogenic and stress relief treatments on temper carbide precipitation in AISI D2 tool steel. International Heat Treatment and Surface Engineering 2013, 7, 120-124.

28. Tyshchenko, A.I.; Theisen, W.; Oppenkowski, A.; Siebert, S.; Razumov, O.N.; Skoblik, A.P.; Sirosh, V.A.; Petrov, Y.N.; Gavriljuk, V.G.. Low-temperature martensitic transformation and deep cryogenic treatment of a tool steel. Materials Science and Engineering: A 2010, 527, 7027-7039.

29. Yun, D.; Lin, X.; Xiao H. Deep Cryogenic treatment of high-speed steel and its mechanism. Heat Treatment of Metals 1998, 3, 55-59.

30. Das, A.; Dutta, A.K.; Toppo, V.; Ray, K.K. Effect of deep cryogenic treatment on the carbide precipitation and tribological behavior of D2 steel. Materials and Manufacturing Processes 2007, 22, 474-480.

31. Huang, J. Y.; Zhu, Y.T.; Liao, X.Z.; Beyerlein, I.J.; Bourke, M.A.; Mitchell, T.E. Microstructure of cryogenic treated M2 tool steel. Materials Science and Engineering: A 2003, 339, 241-244.

32. Cozza, R.C.; Tanaka, D.K.; Souza, R.M. Friction coefficient and wear mode transition in micro-scale abrasion tests. Tribology International, 2011, 44, 1878-1889. 
33. Cozza, R.C.; Rodrigues, L.C.; Schön, C.G. Analysis of the micro-abrasive wear behavior of an iron aluminide alloy under ambient and high-temperature conditions. Wear 2015, 330-331, 250-260.

34. Krelling, A.P.; Da Costa, C.E.; Milan, J.C.G.; Almeida, E. A.S. Micro-abrasive wear mechanisms of borided AISI 1020 steel. Tribology International 2017, 111, 234-242.

35. Bryson, W.E. Cryogenics. Cincinnati, OH: Hanser Gardner Publications, 1999.

36. Da Silva, W.M.; Binder, R.; De Mello, J.D.B. Abrasive wear of steam-treated sintered iron. Wear 2004, 258, 166-177.

37. Trezona, R.I.; Allsopp, D.N.; Hutchings, I.M. Transitions between two-body and three-body abrasive wear: influence of test conditions in the microscale abrasive wear test. Wear 1999, 225-229, 205-214.

38. Trezona, R.I.; Hutchings, I.M. Three-body abrasive wear testing of soft materials. Wear 1999, 233-235, 209-221.

39. Zurecki, Z. Cryogenic Quenching of Steel Revisited. Air Products and Chemicals, Pennsylvania, USA, 2005.

40. Dixit, S.S.; Nimbalkar, S.R.; Kharde, R.R. Dry Sliding Wear Analysis of D5 Tool Steel at Different Heat Treatments. The International Journal Of Engineering And Science 2013, 2, 16-26.

41. Baldissera, P. Fatigue scatter reduction through deep cryogenic treatment on the $18 \mathrm{NiCrMo5}$ carburized steel. Materials and Design 2009, 30, 3636-3642.

42. Vahdat, S.E.; Nategh, S.; Mirdamadi, S. Microstructure and tensile properties of $45 \mathrm{WCrV7} \mathrm{tool} \mathrm{steel} \mathrm{after}$ deep cryogenic treatment. Materials Science \& Engineering A 2013, 585, 444-454.

43. Baldissera, P.; Delprete, C. Effects of deep cryogenic treatment on static mechanical properties of 18NiCrMo5 carburized steel. Materials \& Design 2009, 30, 1435-1440.

44. Barbé, L.; Conlon, K.; De Cooman, B.C. Characterization of the metastable austenite in low-alloy FeCMnSi TRIP-aided steel by nêutron diffraction. Zeitschrift für Metallkunde 2002, 94, 1217-1227.

45. Gulyaev, A. Cold treatment of steel. Metal Science and Heat Treatment 1998, 40, 449-455.

46. Gee, M.G.; Gant, A.; Hutchings, I.; Bethke, R.; Schiffman, K.; Van Acker, K.; Poulat, S.; Gachon, Y.; Von Stebut, J. Progress towards standardisation of ball cratering. Wear 2003, 255, 1-13. 